\title{
PERENCANAAN FRAMWORK ZACHMAN DALAM ENTERPRISE RESOURSE PLANNING SISTEM INFORMASI PADA PT SARANA PEMBAGUNAN PALEMBANG JAYA (SP2J)
}

\author{
Nia Novita Sari ${ }^{1}$, Novri Hadinata ${ }^{2}$, Rahayu Amalia ${ }^{3}$ \\ 1,2,3 Fakultas Ilmu Komputer Universitas Bina Darma, Palembang, Indonesia \\ E-mail : nianovitasari113@gmail.com ${ }^{1}$, novri_hadinata@binadarma.ac.id ${ }^{2}$, \\ rahayu_amalia@binadarma.ac.id ${ }^{3}$
}

\begin{abstract}
In the design of Enterprice Resource Planning (ERP), it takes palnning organized, since the ERP aimed ti integrate the entire process that exists in different funcsional domains of the company, interdeparmental, or between diffrent locations. This research aims to design a blueprint for gentting application esign application in the module inventory Managamnt (IM) Zachman Framwork (ZF) is a framwork that can chart the artifact information architecture in an (Planner,Owner Perspective Perspective, Designer, Builder, Implementer Perspective perspective) appropriate abstraction object (What, How, Where, Who, When, and Why). To standardize information architechure artifacts used modeling standard UML 2.0 approach so it able to improve the desription of the standard Model of ZF be Driven Architecture. For testing the results of design has developed ERP software IM appling model driven design that is able to convert a model artifact quality application. Where the assessment of the testing of the system stakeholdrs in PT.SP2J. obtained an average satisfaction rate of $90 \%$ as for the assessment of availablity system quantitatively compared with Openerp with Openerp 7.0 which only has limited features of $77.7 \%$. Keyword : Enterprise Resoure Planning, Inventory management, Zachman Framwork, UML 2.0 Model Driven Design Openep 7.0.
\end{abstract}

Keywords: ERP, Inventory management, Zachman Framwork, Model Driven Design Openep 7.0

\begin{abstract}
Abstrak
Dalam perencanaan Enterprise Resource planning (ERP), dibutuhkan perencanaan terorganisir, dikarenakan ERP ditunjukan untuk mengintregrasikan seluruh proses yang ada dalam berbagai domain fungsional perusahaan, antar dapartermen, maupun antar lokasi yang berbeda. Penelitian ini bertujuan merancang sebuah desain aplikasi untu $\mathrm{k}$ mendapakan blueprint aplaksi pada modul invevtory management (IM) .zachman framework (ZF) merupakan salah satu kerangka kerja yang dapat memetakan artifak arsiktektur informamasi di sebuah organisasi. Dalam menerapnya, ZF mampu mendeskripsikan level prespektif arsitektur IT (planner perspective, owner perspective, Desingner Perspective, Builder Perspective, Implemennter persspective, participant perspective) sesuai abstraksi objek (untuk srandarisasi artifak arsitektur informasi digunakan pendekatan standart pemodelan UML 2.0, (what, How, Where ,Who, When,Why),sehingga mampu meningkatkan deskripsi ZF menjadi standar model Driven Architecture . untuk menguji hasil desain perancangan telah dikembangkan perangkat lunak ERP IM yang menerapkan model Driven Desingn yang mampu mengkonversi artifak model menjadi aplikasi yang berkualitas dimana dari hasil penilaian Stakenholder dari pengujian sistem di PT. SP2J (Sarana Pembangunan Palembang Jaya), didapatkan tingkat kepuasan rata rata $90 \%$. Sedangkan untuk penilaian availdility sistem secara kuantitatif dengan dibandingkan Openerp 7.0 sistem yang dikembangkan jauh lebih komfeleks dengan ketersediaan pitur $88,8 \%$ berbanding dengan Opernerp 7.0 yang hanya memiliki keterbatasan fitur $77,7 \%$.
\end{abstract}

Kata Kunci: ERP, Inventory management, Zachman Framwork, Model Driven Design Openep 7.0 


\section{Pendahuluan}

Pada beberapa tahun belakangan ini persaingan dalam dunia industri dinegara Indonesia menjadi sangat ketat, apalagi dengan adanya perusahaan pendatang baru (newcomer) yang ternyata memiliki kekuatan jauh lebih fit.Perusahaan yang sudah lama berdiri harus berani bersaing dengan perusahaan-perusahaan pendatang baru lain lebih keras lagi, ditambah lagi dengan dicabutnya kuota perdagangan tekstil pada tahun 2005 silam. Di lain pihak, dengan adanya kelemahan-kelemahan kondisi perekonomian dunia yang mengakibatkan turunnya daya beli yang dapat mengurangi kebutuhan,sehingga akan menyebabkan terjadinya suatu tren dimana persediaan (supply) melebihi permintaan (demand) pasar. Zachman framework merupakan framework arsitektural yang paling dikenal dan diapdaptasi. Para arsitek data enterprise mulai menerima dan menggunakan framework ini sejak pertama kali diperkenalkan oleh jhon A zachman di IBM system journal pada tahun 1987 dan kemudian dikembangkan pada tahun 1992 dengan tujuan untuk meyediakan struktur dasar organisasi yang mendukung akses, integrasi, interprtasi, pengembangan, pengelolan, dan perubahan perangkat arsitektur dari sistem informasi organisasi (enterprise).

ENTERPRISE ARCHITECTUR- A FRAMWORK

\begin{tabular}{|c|c|c|c|c|c|c|}
\hline $\begin{array}{l}\text { abstraction } \\
\text { perspectwes }\end{array}$ & $\begin{array}{l}\text { ns DATA } \\
\text { What }\end{array}$ & $\begin{array}{l}\text { FUNCTION } \\
\text { How }\end{array}$ & $\begin{array}{l}\text { NETWOFK } \\
\text { where }\end{array}$ & $\begin{array}{c}\text { PEOPLE } \\
\text { Who }\end{array}$ & $\begin{array}{l}\text { TWE } \\
\text { When }\end{array}$ & $\begin{array}{l}\text { BOTIVATION } \\
\text { Why }\end{array}$ \\
\hline $\begin{array}{l}\text { SCOPE } \\
\text { Planner } \\
\text { contextual }\end{array}$ & $\begin{array}{l}\text { List or Things - } \\
\text { important to the } \\
\text { Bussiness }\end{array}$ & $\begin{array}{l}\text { Listorpi } \\
\text { the } 80, \\
\text { Aent }\end{array}$ & $\begin{array}{l}\text { List of Locations - } \\
\text { in which the } \\
\text { Business Opeerates }\end{array}$ & $\begin{array}{l}\text { Costroi } \\
\text { Organizasions - } \\
\text { impoontant so the } \\
\text { Busind }\end{array}$ & $\begin{array}{l}\text { List or Events - } \\
\text { Significant to the } \\
\text { Business }\end{array}$ & $\begin{array}{l}\text { Distof } \\
\text { Business } \\
\text { Goals and } \\
\text { Stra }\end{array}$ \\
\hline $\begin{array}{c}\text { ENTERPRISE } \\
\text { MOOEL } \\
\text { Owner } \\
\text { conceptual }\end{array}$ & e.9.5 & $\begin{array}{l}e .9 .6 \\
\text { Proce }\end{array}$ & ${ }_{\mathrm{N}}^{e .9}$ & $\begin{array}{l}\text { 9.9. Work Flow } \\
\text { Model }\end{array}$ & es & e.g. \\
\hline $\begin{array}{l}\text { SYSTEM } \\
\text { MODEL } \\
\text { Designet } \\
\text { logical }\end{array}$ & $\begin{array}{l}\text { e.g., Logical } \\
\text { Data Model }\end{array}$ & $\begin{array}{l}\text { e.g. Application } \\
\text { Architpcture }\end{array}$ & $\begin{array}{l}\text { e.g. Dis } \\
\text { Syst } \\
\text { Archit }\end{array}$ & $\begin{array}{l}\text { e.g. Human } \\
\text { interface } \\
\text { Anchiegcture } \\
\text { 호. }\end{array}$ & $\begin{array}{l}\text { e.9. Processing } \\
\text { Structure }\end{array}$ & e.gut \\
\hline $\begin{array}{l}\text { TECHNOLOOY } \\
\text { CONNTRRANEO } \\
\text { MOOEL } \\
\text { Bullod } \\
\end{array}$ & $\begin{array}{l}\text { e.g. Physical } \\
\text { Oata Model }\end{array}$ & $\begin{array}{c}\text { e.g. System } \\
\text { Design }\end{array}$ & $\begin{array}{l}\text { e.g. }{ }^{\top} \\
\text { Arch }\end{array}$ & $\begin{array}{l}\text { e.g. Presentation } \\
\text { Architecture }\end{array}$ & $\begin{array}{l}\text { e.g. Control } \\
\text { Stucture }=\end{array}$ & e.g. \\
\hline $\begin{array}{l}\text { DETAlLED } \\
\text { REPRESEN } \\
\text { TATIONS } \\
\text { Subcontractor } \\
\text { out- of contex }\end{array}$ & $\begin{array}{l}\text { e.g. Data } \\
\text { Definition }\end{array}$ & e.g. Program & $\begin{array}{l}\text { e.g. Network } \\
\text { Architecture }\end{array}$ & $\begin{array}{l}\text { e.g. Security } \\
\text { Apchitecture }\end{array}$ & $\begin{array}{l}\text { e. Timing } \\
\text { Definitoon }\end{array}$ & $\begin{array}{l}\text { e.g. Rule } \\
\text { specification }\end{array}$ \\
\hline 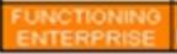 & \begin{tabular}{|c|} 
DAIA \\
Implementation \\
\end{tabular} & 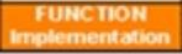 & \begin{tabular}{|c|} 
NETWCorKK \\
Implementation
\end{tabular} & 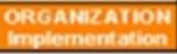 & \begin{tabular}{|l|} 
SCFIEDULE \\
Impitementation \\
\end{tabular} & $\begin{array}{l}\text { STRATEGY } \\
\text { molementetion }\end{array}$ \\
\hline
\end{tabular}

Gambar 1 Kerangka Kerja Zachman Untuk Arsitektur Enterprise

Gambar 1 dijelaskan bahwa zachman framwork merupakan matrik 6x6 yang merespresantasikan interseksi dari dua skema klasifikasi-arsitektur sistem dua dimensi. Pada dimensi pertama, zachman menggambarkan sebagai baris yang terdiri dari 6 perspektif.

a. Planner perpective (Scope Context) : Daftar lngkup penjelasan unsur bisnis yang dikenali oleh para ahli strategi sebagai ahli teori.

b. Owner perpective (Business Concept) : Model semantik keterhubungan bisnis antara komponenkomponen bisnis yang didefinisikan oleh pemimpin eksekutif sebagai pemilik.

c. Designer Perpective (System Logic) : Model logika yang lebih rinci yang berisi kebutuhan dan desain batasan sistem yang direpresentasikan oleh para arsitek sebagai desainer.

d. Builder perpective (Technology Physics): Model fisik yang mengoptimalkan desain untuk kebutuhan spektif dalam batasan teknologi spektif, orang, biaya dan lingkup waktu yang dispesifikasikan oleh engineer sebagai builder.

e. Implementer Perspective (Component Assemblies) :Teknologikhusus, tentang bagaimanakomponen dirakit dan dioperasikan, dikonfigurasikan oleh teknisi sebagai implementator.)

f. Participant Perspective (Operation Classes) :Kejadian-kejadiansistem berfungsi nyata yangdigunakan oleh para teknisi sebagai participant. 
Untuk dimensi kedua, setiap isu perspektif membutukan cara yang berbeda untuk menjawab pertanyaan fundamental : who, what, why, when, where and how. Setiap pertanyaan membutuhkan jawaban dalam format yang berbeda. Zachman menggambarkan setiap pertanyaan fundamental dalam bentuk kolam fokus.

a. What (kolom data) : material yang digunakan untuk membangun system (inventory set).

b. How (kolom fungsi) : melaksanakan aktivitas (process transformations).

c. Where (kolom jaringan) : lokasi, tofografi dan teknologi(network nodes).

d. Who (kolom orang) : aturan dan organisasi (organization group).

e. When (kolom waktu) : kejadian, siklus, jadwal (time periods).

f. Why (kolom tujuan) : tujuan, motivasi dan inisiatif (motivation reason).

Enterprise Resource Planning (ERP) merupakan suatu cara untuk mengelola sumber daya perusahaan dengan menggunakan teknologi informasi. Penggunaan ERP yang dilengkapi dengan hardware dan software untuk mengkoordinasi dan mengintegrasikan data informasi pada setiap area business processes untuk menghasilkan pengambilan keputusan yang cepat karena menyediakan analisa dan laporan keuangan yang cepat, laporan penjualan yang on time, laporan produksi dan inventory yang dihadapi perusahaan saat ini.

Seiring dengan persaingan di dunia bisnis semakin kompleks, maka perusahaanperusahaan mencoba untuk meningkatkan jumlah konsumennya dengan melakukan pelayanan yang cepat dan biaya yang murah dibandingkan dengan kompetitornya. Salah satu cara untuk mewujudkan kesuksesan tersebut dapat dilakukan dengan cara mengintegrasikan sistem informasi, peningkatan efisiensi dari sistem informasi untuk menghasilkan manajemen yang lebih efisien dalam business processes.

Modul Inventory Management (IM) adalah sistem manajemen dalam menentukan keseimbangan antara investasi penyimpanan persediaan dengan pelayanan pelanggan. Sistem persediaan adalah salah satu bagian Zachman Framework merupakan framework arsitekural yang paling banyak dikenal dan diadaptasi. Para arsitek data enterprise mulai menerima dan menggunakan framework ini sejak pertama kali diperkenalkan oleh John A Zachman diIBM System Journal pada tahun 1987 oleh Zachman Institut for Framework Advancement (ZIFA) atas pemikiran John A Zachman [2] [3].

\section{Metodologi Penelitian}

Dalam penelitian ini yang digunakan adalah jenis penelitian kualitatif dengan cara mencari data-data yang berasal dari informasi-informasi melalui para informan yang tidak memerlukan analisa penghitungan (Moleong, 2006). Para peneliti kualitatif sedapat mungkin berinteraksi secara langsung dengan informan, mengenal secara dekat dunia mereka, mengamati, dan mengikuti alur kehidupan informan secara apa adanya. (Rianse, 2009:7). Hal ini dilakukan sebagai upaya peneliti dalam mengkaji data subyek penelitian secara mendalam dan objektif karena tanpa adanya penghitungan, maka informasi-informasi dari para informan sangat urgen keberadaannya.

Fokus dalam penelitian ini adalah : Implementasi sistem ERP (Enterprise Resource Planning) pada PT. SP2J (Sarana Pembagunan Palembang Jaya). Untuk mencapai tujuan analisis kualitatif, tahapan penelitian yang digunakan adalah sebagai berikut:

1. Tahap Pendeskripsian Pada tahap ini peneliti memasuki obyek tempat penelitian, selanjutnya peneliti membaca, melihat gambar, berpikir, melihat aktivitas actors (pelaku) dan kemudian mendeskripsikan apa yang dilihat, didengar dan dirasakan dalam suatu tulisan, untuk kemudian dibuat suatu kesimpulan.

2. Tahap Reduksi Data Pada tahap ini peneliti melakukan wawancara kepada beberapa informan yang berhubungan dengan sistem, dan selanjutnya data dari hasil wawancara tersebut kemudian direduksi. Tahap reduksi data diartikan secara sempit sebagai proses pengurangan data, namun dalam arti yang lebih luas adalah proses penyempurnaan data, baik pengurangan terhadap data yang kurang perlu dan tidak relevan, maupun penambahan terhadap data yang dirasa masih kurang. Data dari hasil wawancara kemudian dibandingkan dengan data hasil observasi dan dokumentasi di lapangan untuk kemudian dibuat suatu kesimpulan. 
3. Tahap Analisis Pada tahap ini, peneliti mengurai fokus masalah yang ditetapkan secara rinci untuk kemudian dicari pemecahan masalahnya dengan memberikan solusi atau rekomendasi terkait sistem informasi yang meliputi: teknologi informasi, sistem informasi, pengumpulan data, penyimpanan, pemeliharaan, keamanan, organisasi, dan pengambilan kembali.

4. Proposisi Hasil dari penelitian ini adalah berupa proposisi atau dugaan bahwa analisis data kualitatif mencakup tiga alur kegiatan yaitu reduksi data, penyajian data, dan penarikan kesimpulan. Pada penarikan kesimpulan dilakukan ketika peneliti mencatat keteraturan, penjelasan, dan proposisi.

Tahapan ini merupakan tahap persiapan dan permulaan untuk mendefinisikan kerangka dan prinsip yang bertujuan untuk mengkonfirmasi komitmen dari manajemen, penentuan kerangka kerja dan rincian metodologi yang akan digunakan pada perancangan enterprise arsitektur. Adapun tahapan yang dilakukan di dalam fase ini adalah sebagai berikut:

1. Penentuan lingkup arsitektur enterprise yang digambarkan melalui value chain.

2. Identifikasi stakeholder yang terlibat berdasarkan aktifitas value chain.

3. Identifikasi prinsip arsitektur yang digunakan di dalam perusahaan.

4. Penentuan framework. Pada penelitian ini framework yang digunakan adalahzachman framework.

5. Penentuan tools yang akan digunakan. Tools yang akan digunakan adalah value chain, diagram UML

\section{Hasil dan Pembahasan}

Setelah melakukan analisa dan perancangan sistem, maka hasil yang dicapai oleh penulis adalah sebuahSistem Informasi Pelayanan Pelanggan Pada PT. SP2J Unit Usaha Pengelola Jaringan Gas Kota Palembang Dengan Menggunakan Metode Zachman Framework untuk memudahkan PT. SP2J Unit Usaha Pengelola Jaringan Gas Kota Palembang dalam melakukan kegiatan pelayanan pelanggan.

Tabel 1. Hasil Matrik Sistem Informasi Pelayanan Pelanggan PT. SP2J Unit Usaha Pengelola Jaringan Gas Kota Palembang Dengan Menggunakan Metode Zachman Framework

\begin{tabular}{|c|c|c|c|c|c|c|}
\hline $\begin{array}{l}\text { Abstraksi/ } \\
\text { Perspektif }\end{array}$ & $\begin{array}{l}\text { 1. Data } \\
\text { What }\end{array}$ & $\begin{array}{l}\text { 2. Function } \\
\text { How }\end{array}$ & $\begin{array}{l}\text { 3. Network } \\
\text { Where }\end{array}$ & $\begin{array}{l}\text { 4. People } \\
\text { Who }\end{array}$ & $\begin{array}{l}\text { 5. Time } \\
\text { When }\end{array}$ & $\begin{array}{l}\text { 6. Motivation } \\
\text { Why }\end{array}$ \\
\hline $\begin{array}{l}\text { A. Planer/ } \\
\text { conceptual } \\
\text { (scope) }\end{array}$ & $\begin{array}{l}\text { Data Pelanggan } \\
\text { Data Produk } \\
\text { Data Angsuran } \\
\text { Data Denda }\end{array}$ & $\begin{array}{c}\text { Proses pendaftaran } \\
\text { pelanggan, validasi data } \\
\text { pelanggan, cek angsuran, } \\
\text { cek tunggakan }\end{array}$ & $\begin{array}{l}\text { Daftar lokasi Bagian } \\
\text { EDP, Teknis dan } \\
\text { Pelayanan, Dan } \\
\text { Pimpinan }\end{array}$ & $\begin{array}{l}\text { Pengguna terdin dani } \\
\text { Pimpinan, Teknis dan } \\
\text { Pelayanan, } \\
\text { Bagian EDP, Pengguna } \\
\text { (masyarakat) }\end{array}$ & cakupan arsitekru & Visi dan Misi \\
\hline $\begin{array}{c}\text { B. Owner/ } \\
\text { conceptual } \\
\text { (Business Model) }\end{array}$ & $\begin{array}{l}\text { Pemodelan dan } \\
\text { Usecase System }\end{array}$ & Sequence diagram & $\begin{array}{l}\text { Desain lokasi Bagian } \\
\text { Inormasi, Teknis dan } \\
\text { Pelayanan dan } \\
\text { Pimpinan }\end{array}$ & Struktur enterprise & Major event & $\begin{array}{l}\text { Perencanaan jangka } \\
\text { panjang }\end{array}$ \\
\hline $\begin{array}{l}\text { C. Designer/ } \\
\text { (System Model) }\end{array}$ & $\begin{array}{l}\text { Entity Relation } \\
\text { Diagram Bisnis } \\
\text { (ERD) }\end{array}$ & Activity Diagram & $\begin{array}{l}\text { Desain Jaringan Logis } \\
\text { PT SP2J }\end{array}$ & Peran Entitas & Rencana kegiatan pelayanan & $\begin{array}{c}\text { Perencanaan System } \\
\text { model }\end{array}$ \\
\hline $\begin{array}{c}\text { D. Builder } \\
\text { (Technology Model) }\end{array}$ & Class Diagram & $\begin{array}{l}\text { Rancangan Interface } \\
\text { Pengguna }\end{array}$ & $\begin{array}{c}\text { Desain arsitektur skema } \\
\text { Jaringan Usulan PT } \\
\text { SP2J }\end{array}$ & $\begin{array}{l}\text { Desknipsi struktur } \\
\text { organisasi }\end{array}$ & $\begin{array}{l}\text { Rencana kegiatan desain } \\
\text { model }\end{array}$ & $\begin{array}{l}\text { Aturan-Aturan dalam } \\
\text { Pembuatan Desain }\end{array}$ \\
\hline $\begin{array}{l}\quad \text { E. Detailed } \\
\text { Representation } \\
\text { (Sub-Contractor) }\end{array}$ & Pembuatan Tabel & Arsitektur hak akses & $\begin{array}{l}\text { Arsitektur jaringan } \\
\text { fisik }\end{array}$ & Arsitektur keamanan & $\begin{array}{c}\text { Definisi waktu } \\
\text { penggunaan sistem }\end{array}$ & $\begin{array}{l}\text { Aturan-atura dalam } \\
\text { program logis }\end{array}$ \\
\hline
\end{tabular}

\subsection{Pada Data (What)}

Kolom Model Sistem atau System Model mendefinisikan model sistem bagi data dengan mengidentifikasi model data logis.Model ini dapat berupa Diagram Standard dari entitasentitas data dan relasi-relasi antara mereka berdasarkan hasil dua perpektif sebelumnya. Sistem Model merupakan pembahasan lanjut yang telah diuraikan pada Enterprise Model. Melakukan Pendaftaran Informasi 
Produk Pelanggan Cek Pembayaran Validasi Pendaftaran Bagian EDP Kelola Pembayaran Survey Bagian Teknis dan pelayanan pelanggan Instalasi Pimpinan Laporan.

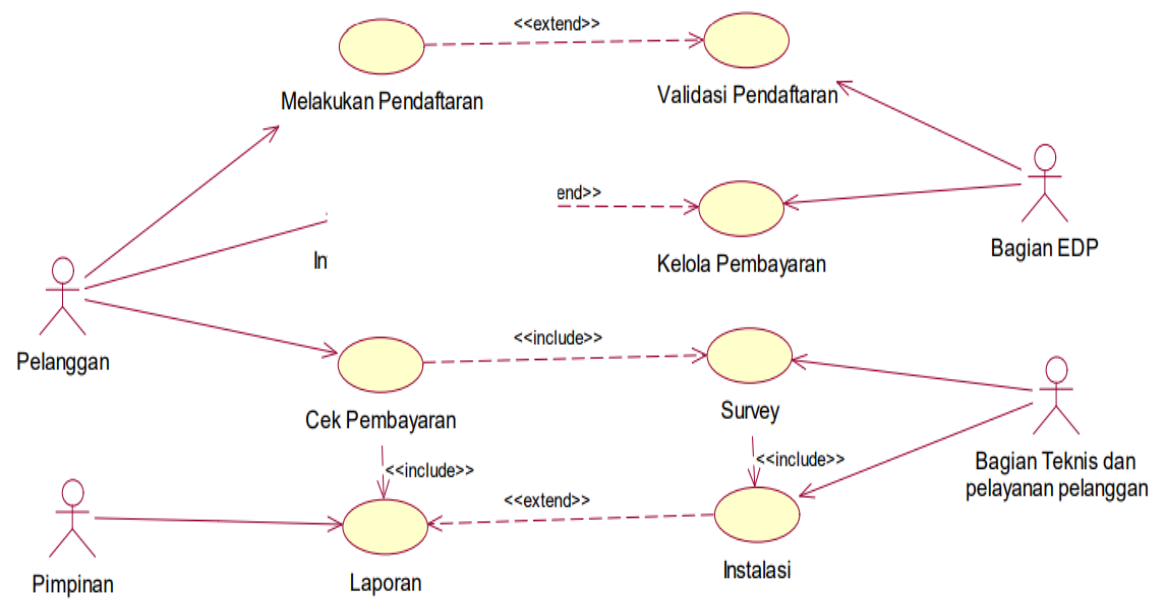

Gambar 2. Usecase Diagram

\subsection{Pada Fungsi (How)}

Mendefinisikan model enterprise dengan memaparkan proses bisnis mencakup dekomposisi dan/atau ketergantungan antara aktivitas-aktivitas bisnis. Proses bisnis sistem informasi pelayanan pelanggan di PT. SP2J Unit Usaha Pengelola Jaringan Gas Kota Palembang.

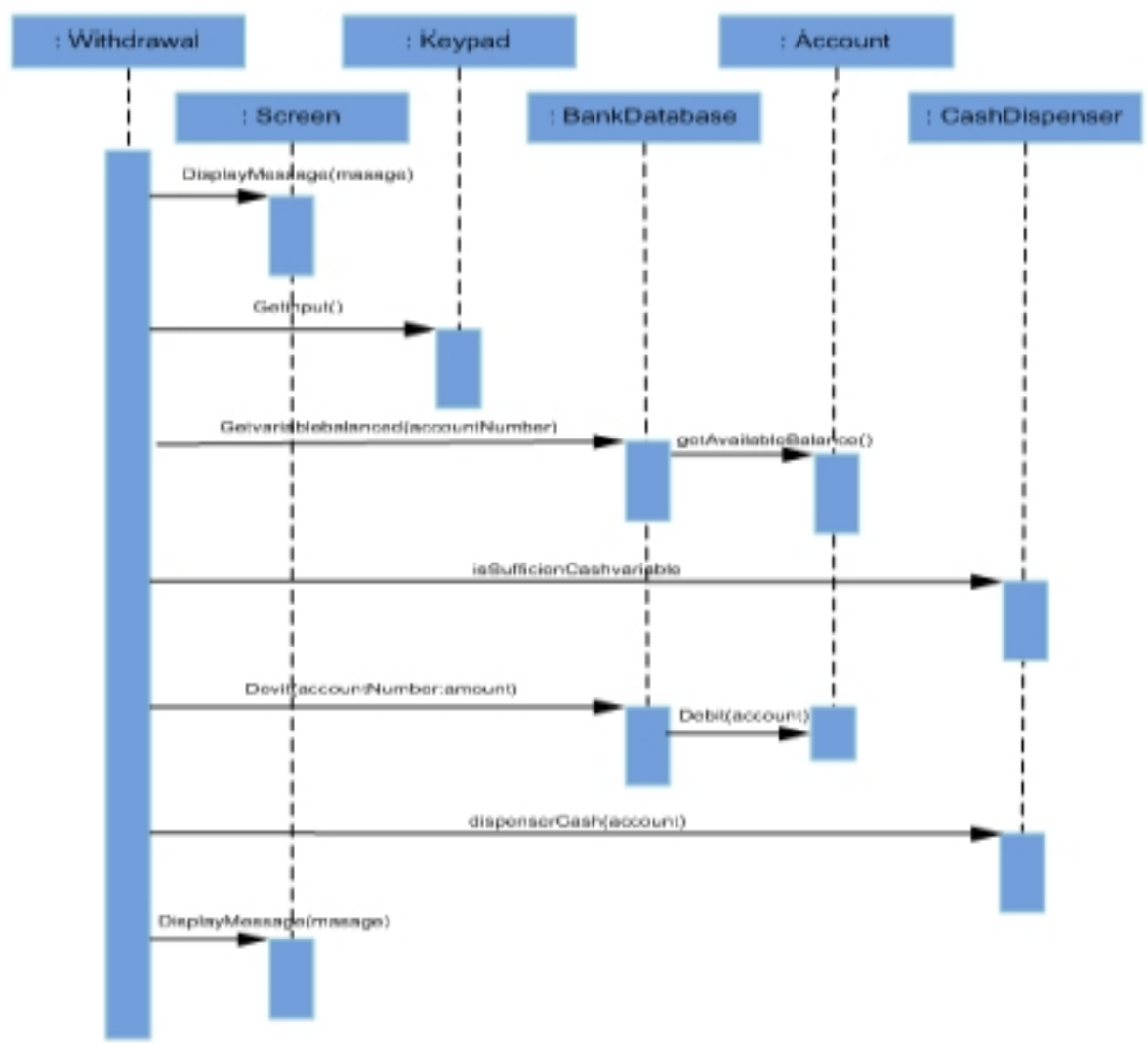

Gambar 3 Proses Bisnis Sistem Pelayanan Nasabah 


\subsection{Pada Jaringan (Where)}

Mendefinisikan arsitektur jaringan logis yang terdiri dari model sistem jaringan dan arsitektur sistem terdistribusi. Bagian sistem model menggambarkan sistem link topologi / sekenario jaringan PT. SP2J Unit Usaha Pengelola Jaringan Gas Kota Palembang Palembang. Berikut ini merupakan gambar skenario Jaringan PT. SP2J Unit Usaha Pengelola Jaringan Gas Kota Palembang Palembang.

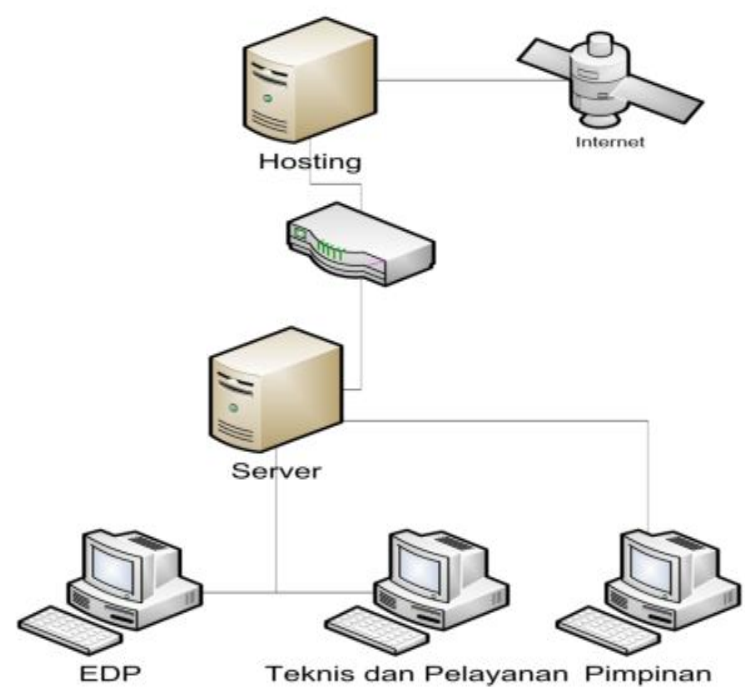

Gambar 4. Skenario Jaringan Domain PT. SP2J Unit Usaha Pengelola Jaringan Gas Kota Palembang

\subsection{Pada Orang (Who)}

Berikut ini merupakan data peran setiap entitas yang ada di PT. SP2J Unit Usaha Pengelola Jaringan Gas Kota Palembang Palembang

Tabel 1 Peran Unit Organisasi PT. SP2J Unit Usaha Pengelola Jaringan Gas Kota Palembang. Unit

\begin{tabular}{|l|l|}
\hline \multicolumn{2}{|c|}{ Unit Organisasi } \\
\hline Pimpinan & Prgani Peranan \\
\hline EDP & Bagian EDP mengelola data pelanggan \\
\hline $\begin{array}{l}\text { Teknis dan pelayanan } \\
\text { pelanggan }\end{array}$ & Survey mengelola data Teknis dan pelayanan pelanggan \\
\hline Pelanggan & $\begin{array}{l}\text { Pelanggan melakukan pendaftaran, melihat pembayaran, } \\
\text { melihat tunggakan. }\end{array}$ \\
\hline
\end{tabular}

\subsection{Pada Waktu (When)}

Kolom model sistem atau System Model mendefinisikan model sistem yang terdiri dari struktur pemrosesan.Waktu dalam hal ini adalah waktu dari kejadian sistem, sedangkan siklus dalam hal ini adalah siklus pemrosesan. Bagian ini menguraikan pengaturan waktu atau penjadwalan berdasarkan periode waktu tertentu PT. SP2J Unit Usaha Pengelola Jaringan Gas Kota Palembang. Dari rencana kegiatan pelayanan pelanggan PT. SP2J Unit Usaha Pengelola Jaringan Gas Kota Palembang diatas dimana pelayanan pelanggan dalam dilakukan pada bulan juli. 


\subsection{Pada Kolom Motivasi (Why)}

Menjelaskan aturan-aturan yang digunakan dalam pembuatan designer yaitu:

1. Bahasa pemerograman yang akan digunakan bersifat opensourse, sehingga yang dikeluarkan tidak terlalu besar.

2. Adapun bahasa pemerograman yaitu PHP dan HTML.

3. Data base yang digunakan adalah MYSQL.

4. Tampilan menggunakan Web.

\section{Kesimpulan}

Penyusunan dokumen yang mendefinisikan organisasi secara lengkap merupakan hal yang bermanfaat. Penulis menyarankan kepada pengembang selanjutnya untuk menerapkan hal yang sama. Akan lebih baikapabila setiap Dinas terkait memahami manfaat dari Enterprise Architecture agar organisasi dapat terdefinisi dengan mantap dan data bisatersentralisasi.Pada saat ini, penulis mencapai tahap pendefinisian organisasi dimana datadiperoleh dari hasil wawancara dan analisis organisasi.Bagi pengembangselanjutnya penulis menyarankan untuk selalu membuat data-data dalamdokumen ini up to date sehingga manajementingkat atas dapat terusmemantau peningkatan-peningkatan yang terjadi bagi kekurangan-kekurangan yang ditemukan atas Sistem Informasi Pelayanan Pelanggan di PT. SP2J Unit Usaha Pengelola Jaringan Gas Kota Palembang.

\section{References}

[1] John A Zachman diIBM System Journal pada tahun 1987 oleh Zachman Institut for Framework Advancement (ZIFA) atas pemikiran John A Zachman.

[2] Jhon A zachman di IBM system journal pada tahun 1987 dan kemudian dikembangkan pada tahun 1992.

[3] Daftar gaji dan sumber daya manusia Menurut wallace dan kremzar $(2001 ; 12)$ tujuan diterapkan ERP.

[4] Perangkat Lunak ERP adapun Keterbatasan ERP Menurut Leon (2000;37).

[5] Hanya beberapa Ketukan Di Keyborrd ( information in your fingertips) Menurut Hartono (2004; 10) untuk membagun sistem ERP.

[6] Perangkat lunak yang dibutuhkan untuk membagun sebuah sistem Menurut Hartono (2004; 13).

[7] Tahapan implementasi sistem ERP ini Menurut Leon (2000; 108)

[8] James Rumbaugh, Grady Boach dan Ivar Jacobson, yang masing-masing telah mengembangkan notasi mereka sendiri di awal tahun 1990an. 
JURNAL

NASIONAL

ILMU

KOMPUTER
Jurnal Nasional Ilmu Komputer e-ISSN: 2746-1343

Vol. 1, No. 4, November 2020

Halalaman ini Sengaja Dikosongkan 